\title{
Entre seguridad y bienestar, entre consumo e inversión: entre ética y corrupción: 1992
}

Fco. Javier Ibisate

Una de las preguntas más táciles de hacer y más difíciles de responder es: y usled ¿cómo ve la situación? - Hay lantas formas de ver la situación y lantas limitaciones para abarcarla en su complejidad que uno comienza por cortar a tijera los titulares de los diarios y luego trata de armar todo el mosaico. Ya decía el relrán antiguo que cada uno habla de la feria como le va en ella. Los organismos oficiales que elaboran los datos macroeconómicos nos dicen que el Indice de Volumen de la Actividad Económica (IVAE), el monto de reservas netas y los depósitos bancarios van a mejor y que la economia muestra signos de recuperación. Los empresarios afiliados a la Cámara de Comercio y los agricultores de Oriente acusan al BCR de Irenar, con sus polílicas restrictivas, los flujos de préslamos y comprometer así al mismo IVAE. El hombre corriente de la calle, peatón o inquilino de las camionetas, protesta porque entre el IVA y la inflación sus microeconomías se hacen más microeconomías. Los vecinos de cualquier barrio y los transportistas de cualquier carretera lamentan que la delincuencia sube más de prisa que el produclo nacional. Los sindicatos dicen que todavia se les mira mal y que en el Foro de Concertación Económico-Social se les oye peor. Los excombatientes de ambos lados de las Irincheras se unen para reclamar que la jubilación asignada en tierras o en enseres doméslicos es minusválida y deficiente de cara a un futuro civil y civilizado. La luerza armada, en plural o en singular, lamenla que no se reconozcan sus sacrificios por defender la Conslitución. La Corle Suprema y el Ministerio 
de Justicia prometen multiplicar los juzgados itinerantes para salir a buscar la justicia perdida. UNICEF nos descubre la situación deleriorada de la familia y de la nifez traumatizada por la guerra y la economla. FUNDASALVA lanza una amplla publicidad para trenar el avance de la droga. Los ecologistas nos alertan porque además de pequeho espacio somos el pais relativamente más deteriorado en nuestro ecosistema. El Semanario Proceso llena la mayor parle de sus comentarios con las violaciones a los derechos humanos.

A modo de mala hierba han aparecido los "maximilianos", las cruzadas y los comités que adoran al dios-Moloc y le quieren ofrecer "sangre roja". Pero también hay quienes siguen haciendo memoria de tantos mártires sacrilicados en la cruz del Mozole, Zumpul, Las Hojas, el pozo macabro, el Hospilal de la Divina Providencia, FENASTRAS, la UCA.... para que la memoria del pasado ahorre la sangre del presente. Casi al final del afio los Obispos Latinoamericanos reunidos en Santo Domingo reafirman la consigna calólica de "la opción preferencial por los pobres". Y sobre todo, la gran producción escrila y aclamada por casi todos: los Acuerdos de Paz. Después de doce afios de guerra y más afios de conflicios sociales no es tan tácil que todos jalemos a una de la "cuerda" de la paz. El militarismo, el partidismo, el neoliberalismo, el confusionismo desmembran los hilos de los acuerdos de paz y seguimos tensionados por las leyes de la supervivencia del más fuerte.

No resulta fácil hacer una memoria de 1992 porque ha sido tan polifacético como los 365 dias del año. Es cierto que el primero de enero nos dijimos "Feliz Año Nuevo" y lo repelimos con mayor alegría el 16 del mismo mes, y a comienzos de lebrero... Saltando algunos meses, en los idus de septiembre se alarmaron las mayorías populares cuando la inflación volvio a aligerar el trole $(2,9 \% ; 4,7 \% ; 2,7 \%)$ y aun nos quedan los dos meses finales del año. Tanto o más luerte fue el sobresalio del 31 de oclubre, en que se amenazo con rasgar los Acuerdos de la Paz en nombre de Dios y de la Constilución. Ahora se ha corrido el calendario porque los compromisos pactados seguian sin correr. En el interim si han corrido rumores hasla de golpe de Eslado, de ajusticiamienlos intraguerrilleros cargados a la cuenta del Gobierno, y los que más han corrido de arriba para abajo han sido los representantes de las Naciones Unidas para poner orden en el camino hacia la paz. También otros han corrido a conceder y concederse condecoraciones antes de que se lea en voz alta la lista.

Y usted ¿cómo ve la situación? - Es difícil hablar de todas las fichas de este domino, que se pueden ensamblar de tan diversas formas, sin saber aún quién ganará la partida final. A sabiendas de que puede ha- 
ber un "error de composición" al lomar la parte por el todo, nos vamos a centrar en un doble dilema: seguridad versus bienestar e inversión versus consumo. Eslas son dos expresiones que las podemos encontrar en cualquier lexto de introducción a la Economia: gaslo militar versus gas1o civil; gasto de cara al presenle y deuda externa sin inversión para el futuro. Dos complejas elecciones que van más allá que el calendario de 1992.

\section{Segurldad versus blenestar}

Hace ya bastantes años, a mediados de siglo, las primeras ediciones de P. Samuelson, premio Nobel de economia, nos introducian a los problemas económicos de las naciones con unos gráticos que describen las "Posibilidades de Producción" de cada país o región. Uno de esos gráficos planteaba la siguiente alternativa: CAÑONES O MANTEQUILLA. En una interprelación económica o economicista se nos ensefaba que había que escoger entre la producción de canones o la producción de mantequilla; pro: ducir más de una cosa requeria renunciar a producir más de la otra, porque los recursos son limitados. A un esludiante de aquella época de la Ila posigue-

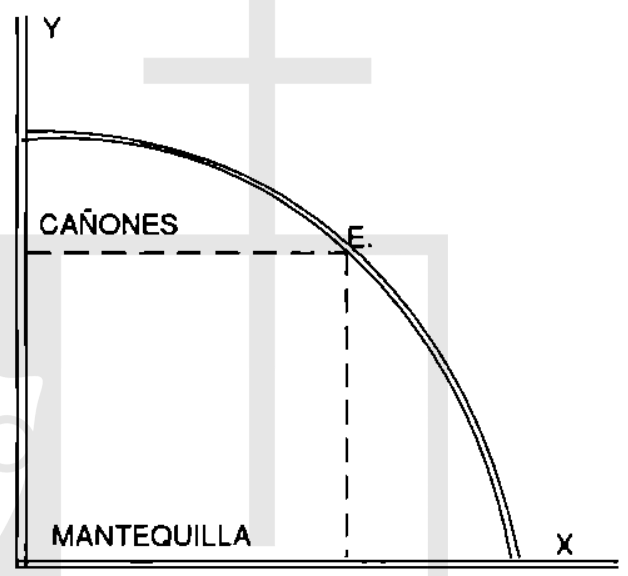
rra mundial no le conmovia mucho esta elección, porque los cafiones le podrian recordar las lantásticas batallas de "lo que el viento se llevó", mientras que se iniciaba la gran "onda larga, 1950-1970" que multiplicaria por cuatro el PTB mundial. Pero ¿qué se estaba escondiendo en ese voluminoso PTB mundial?

Cuarenta años más tarde, 1992, el profesor que explica este gráfico y los alumnos que lo escuchan entienden el diagrama desde una experiencia larga y dolorosa. Ahora hay que comentar la vivencia salvadoreha desde la convivencia mundial, porque el agua que bebemos viene del rio-arriba. Las revislas de geoestrategia muestran que una de las características del siglo del "desarrollo" es que los dos grandes sistemas económicos iniciaron una desenfrenada carrera armamenlística que absorbió el $50 \%$ de aquel producto mundial. "Entre los principales obstáculos a toda limitación de la carrera armanlistica está el gran número de universitarios (quimicos, físicos, biólogos en su mayor parte, aunque no 
sólo ellos) cuyos trabajos de investigación son financiados por el presupuesto militar de las grandes potencias. Asi, por ejemplo, tenemos que más de la milad de los ingenieros y físicos en el mundo trabajan para las necesidades de la delensa. Los fondos asignados, alrededor de $\$ 33$ mil miltones, son netamenle superiores a las cantidades destinadas para la investigación con fines pacíficos. En estos países se han forzado amplias burocracias alrededor de los asuntos militares. Las presiones ejercidas por el grupo integrado por militares, industriales, universitarios y burócratas, con el fin de mantener y elevar los gastos militares, son Ian fuertes que los politicos no pueden hacer otra cosa que ceder a sus demandas"... (ECA, 1982, pp. 903...) Este comentario dala de inicios de 1980 , cuando iba a iniciar nuestro cońlicto armado.

Estos gastos militares alcanzaban, en esos años, la cilra de $\$ 400.000$ millones por año, casi un millón de dólares por minulo, y la cifra casi duplicaria en la década de los ochenta. Puesto todo ello en términos de destrucción, el arsenal alómico equivalía a 1,500.000 bombas Hiroshima. Desde 1950 hasla el inicio de nuestro confliclo ya se habian librado unas 130 guerras, setenla y cinco de las cuales se calificaban como "conlliclos graves"; la mayor parte de eslas guerras han eslallado en el tercer mundo... (ECA, ibidem). Somos hijos de la guerra. Con cuanla razón el aulor de Perestroika luchó hasla donde ha podido para solrenar la "mania armamentislica" que amenazaba con la desaparición de la humanidad. Este giro de la hisloria vino principalmente de un personaje del Esle, mientras que lamenlamos que lodavia en enero de 1991 la prensa norteamericana describiera sus bombardeos en el Medio Oriente como "un árbol de Navidad sobre Bagdad". Somos también aprendices de los grandes aclores de la guerra, que nos han ayudado con miles de millones a hacer la nueslra. Muchos se han alegrado con el cambio presidencial en los Estados Unidos, aunque no taltó quien lamentara que peligraba así su "ayuda humanitaria".

¿Por qué este rodeo sobre el mapa mundial para alerrizar en nuestra pequeña guerra? Porque al momenlo de firmar la paz se sigue falsilicando el origen y el destino de nuestro conllicto armado y, de carambola, se nos impone un modelo económico que arriesga de renovar la confliclividad. Sin ser pródigos en palabras, a nuestra guerra se le sigue distrazando con los uniformes de capilalismo-comunismo, democraciaesclavitud, libentad-terrorismo. Con lo dilicil que es leer y entender a Marx, se ha prodigado la viñela de marxista-leninisla a cuanlos querían aprender a leer, comer, veslirse y alojarse. Se ha perseguido por parejo al Capital y a la Biblia, porque ésla habla del Dios de vida, de la dignidad y de la Iraternidad de los hombres y de una justicia diferente de la que brota de la economia de mercado. Se hizo del comunismo una 
droga terrifica, limpia-cerebros y lan de reacción inmediala que transiormó a sencillos campesinos adscritos a los BIRI en asesinos despiadados de sus hermanos, nifios y mujeres. Al falsificar el origen y las raices profundas de la guerra se desfiguró humanamente a los carapintadas que malaban en nombre de Dios y de la Constitución, y se les sigue llamando "gloriosos".

A modo de oásis en el desierio, el grupo de jóvenes militares, que dieron el golpe en octubre de 1979, veían otras raices internas en las convulsiones sociales de la década, y sintieron que el cúmulo de trusiraciones populares y la pobreza degradante salpicaba también la imagen de su Fuerza Armada. Se acusa al Gobierno "porque ha violado los derechos humanos del conglomerado... Ha lomentado y tolerado la corrupción en la administración pública y de la juslicia... Ha creado un verdadero desastre económico y social... Ha desprestigiado profundamente al país y a la noble institución armada... Convencida de que los problemas anteriormente mencionados son el producto de anticuadas esiructuras económicas, sociales y políticas, que han prevalecido tradicionalmente en el país las que no ofrecen para la mayoria de la población las condiciones minimas necesarias para que puedan realizarse como seres humanos... Conocedora con cerleza de que los gobiemos en turno, productos a su vez de escandalosos fraudes electorales, han adoplado programas inadecuados de desarrollo, en los que los límidos cambios de estructuras planteados han sido Irenados por el poder económico y polilico de sectores conservadores... Firmemente convencida de que las condiciones anteriores son la causa del caos económico y social y de la violencia que se está padeciendo en la actualidad..., por Ianto la Fuerza Armada decide... crear las condiciones para que en nuestro país podamos lodos los salvadorefos tener paz y vivir acorde a la dignidad del ser humano..." (ECA, 1979, pp. 1017-1018; y 1992, pp. 252-253).

A modo de relámpago iluminador, el aclual comandante de las Fuerzas Armadas, Presidente Alfredo Cristiani, se expresó asi en Chapultepec". Nos quedariamos injustamente cortos si viéramos sólo hacia el pasado inmediato para medir la magnilud de lo que sucede en El Salvador. De un liempo a esta parte, la crisis en que se vió envuelta la nación salvadorena, en el último decenio, no surgió de la nada ni fue fruto de voluntades aisladas Esta crisis tan dolorosa y trágica tiene antiguas y profundas raices sociales, políticas, económicas y culturales. En el pasado una de las perniciosas vallas de nuestro esquema de vida nacional fue la inexistencia o insuficiencia de los espacios y mecanismos necesarios para permitir el libre juego de las ideas, el desenvolvimiento nalural de los dislinlos proyectos políticos derivados de la liber- 
tad de pensamienlo y de acción. En sintesis, la ausencia de un verdadero esquema democrálico de vida"... (ECA, 1992, p. 165...). Citamos la bibliografía por si a algunos miembros del Gobierno se les ha extraviado el discurso.

Minutos antes, el Secretario General de las Naciones Unidas habló en inglés muy claro". Lo que esto nos enseña es que las estrategias nacionales de gobierno deben establecerse con la participación de diferentes sectores de la sociedad; que el objetivo central de toda empresa gubernamental debe ser el acrecentamiento del bienestar del pueblo en general; que debe haber cauces para que la gente comunique sus dificullades y busque remediarlas; y que todas las sociedades deben procurar consiantemente esiorzarse por realizar y alcanzar los preceptos de la Declaración Universal de los Derechos Humanos. Esta Declaración abraza un concepto de los derechos humanos que vincula los derechos económicos, sociales y culturales en una relación interdependiente e indivisible con los derechos civiles y polílicos. Sólo con estas estrategias orientadas al pueblo podemos esperar reducir las raíces del conflicto..." (ECA, 1992, p. 155).

Minulos después, en represenlación del FMLN, pronunció su discurso el comandante Shafik Handal". La firma del Acuerdo de Paz marca la culminación de una etapa decisiva en la larga y heroica lucha del pueblo salvadorefio por sus ideales de libertad, justicia, democracia, dignidad humana y progreso... Lo principal de este logro es el fin de la hegemonía militar sobre la nación civil, el tinal de una larguísima época durante la cual fueron ahogados los ideales liberales de los próceres de la independencia en beneficio de una minoría opulenta, apoyada en la fuerza, que llegó a volverse insensible al clamor del pueblo laborioso y pobre. Durante muchísimo tiempo, una y otra vez, los salvadorefios intenlamos cambiar esla situación por vias pacílicas, incluso electorales; pero eslas puerlas fueron cerradas. Fue necesario que nos alzáramos empunando las armas para abrirlas y no nos arrepentimos de ello..." (ECA, 1992, pp. 156-157).

Esta sumatoria de testimonios, que en su día nos dieron le y optimismo, nos ayudan a comprender el conglomerado de melas e ideales que se encierran en la manoseada expresión de "DEMOCRACIA". Además, con estos aulorizados lestimonios vamos a entender mejor nuestro grático actualizado de los cañones y la manlequilla. Si sustituimos, en el eje de coordenadas, la "mantequilla" por eso que nos han dicho que es la "Democracia" y reemplazamos los cańones por los principios de la "Seguridad Nacional" (Pan de Desarrollo, 1978...), comprendemos la interdependencia, o mejor dicho la contraposición hislórica siempre exis- 
lenle, aunque más relevante en las dos últimas décadas. La contraposición o círculo estructural se refuerza cuando la supresión de la democracia engendra la mayor inseguridad nacional (ejemplo: década de los 1970) y cuando se recurre a distrazar la inseguridad nacional con el "sambenito" de agresión internacional. Con esta falsedad lógica, la Constitución ampara el militarismo y

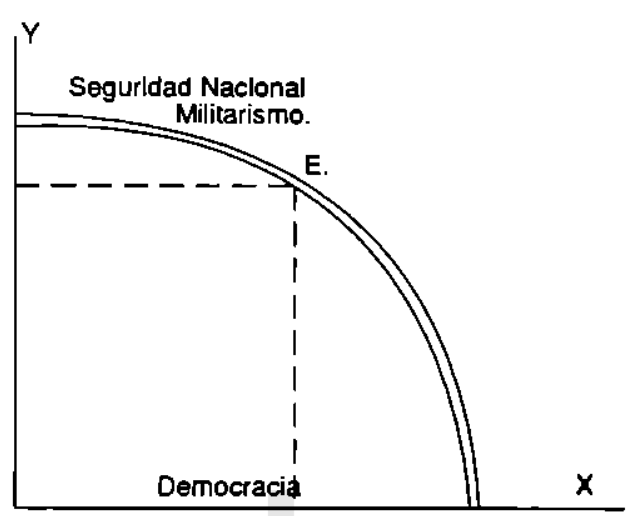
legitima todas las fechorias en nombre de la Palria. Se legaliza la guerra represiva (ordenada del gráfico) y consecuentemente, como un rebrote de la democracia (abscisa del gráfico) se justifica la insurgencia. Esa ha sido la triste historia, 1980-1992, repudiada al unisono en Chapultepec como lo fuera antes en octubre de 1979. Uno de los asesinatos, no el único, que tipifica la falsificación del problema fue intentar apagar "la voz de los sin voz", en la persona de Mons. Romero. Nueve años más tarde se repite "en oclava-mayor" un nuevo intento por apagar las voces universilarias. Pese a todas las declaraciones en Chapultepec, el crimen sigue impune y la impunidad sigue prolegida a la sombra de la "seguridad nacional". Este argumento han blandido, quienes habiendo ayudado y asesorado tanto a la guerra, pudieran ahora ayudar a esclarecer la verdad. Esta es la mínima "ayuda humanitaria" que nos podrian brindar sin poner en peligro su déficit fiscal.

Por supuesto que, tensionado el pais entre "cañones y mantequilla", las curvas de posibilidades de producción se contraen y se hunden. Son estos aspeclos cuanlitativos, los $\$ 4.000$ millones de destrucción bélica, la conlracción del PIB, la brecha de la balanza de pagos..., lo que más ha subrayado el partido ARENA para legitimar otro modelo de seguridad económica nacional. Estos dalos son cierlo como cierto era todo el deterioro macroeconómico, pero no son ahora los principales para sanear la raiz del problema o más bien pueden agravar el problema como lo veremos más adelante. Derivar la alención hacia parámetros macroeconómicos cuantificables como signo de éxito, consciente o inconscientemente es una táclica para relegar al olvido lo que está en el centro de los discursos de Chapultepec y de los Acuerdos de Paz: poner fin a la impunidad militarizada, sentar las bases de la justicia y de los derechos humanos, un proceso de reeducación de militares con o sin unilorme, un 
mecanismo electoral Iransparenle, una policía civil... Es decir, todo un cambio de cultura propia de paises civilizados.

Lo cualitalivo eslá anles y es la base de lo cuanlilativo. Por ello se han creado dos enles, tan necesarios como riesgosos, la Comisión de la VERDAD y la Comisión AD-HOC. Como la palabra depuración no se aplica usualmente a las personas, se la sustiluyó por el bisilabo latino: "ad-hoc" (= para eslo, a tal lin); pero el fin es que se descubra la impunidad y a los hechores de la impunidad. Aunque no hubiera castigo judicial, ya es un gran logro y un buen castigo dar sentencia, nacional e internacionalmente, en conlra de la impunidad como conducla permisible y en contra de sus hechores materiales e intelecluales. Por esta razón, más peligrosas que la sacudidas económicas de sepliembre... han sido las declaraciones oficiales de fines de oclubre, comparsadas por pronunciamienlos anónimos fácilmente idenlificables, que se resisten a la manileslación de la verdad, interponiendo el arancel de la confidencialidad y llexibilidad, lo cual no es sino un hecho más de impunidad. Las declaraciones oficiales del 31 de octubre ...y noviembre no encajan en el discurso pronunciado, desde fuera, el 16 de enero. Los psicólogos dirán si eslamos frente a un caso de doble personalidad. Porque aquellas palabras nos llenaron de optimismo, la UCA creyó necesario ayudar a recuperar la dirección perdida con su pronunciamienlo: "Es hora de cumplir con el pueblo salvadoreño" (Diario Lalino: 6-11-92. La Prensa Grálica; 8-11-92).

Entre esas dos fechas de nuestra publicación, uno de los miembros de la Comisión de la Verdad, el Dr. Thomas Buerghental, declara que la CIA y el Penlágono-USA bloquean las investigaciones de EI Salvador. Con esta declaración se pone en la panlalla a uno de los principales agentes de la impunidad; al apoyar y linanciar la guerra tenian necesariamente que proleger la impunidad y su propia impunidad "por razones de seguridad nacional". ¿Otro Waler-Gale?- En esla declaración Thomas Buerghenlal dice que "la interferencia de esas dependencias (ClA y Pentágono) debilitan cualquier esluerzo para esclarecer horrores de la guerra civil de 12 años en ese país... El Gobierno de los Estados Unidos prometió cooperar y destinó un millón de dólares para financiar el trabajo de la Comisión de la Verdad, pero sus integrantes no han tenido acceso a documenlos confidenciales de la CIA-Pentágono"... Se repiten los mismos obsláculos y ocultamientos que bloquearon el juicio de los autores intelecluales del múltiple asesinalo de la UCA. No habria razones para interponer "motivos de seguridad nacional norteamericana" si no hubiera culpabilidad de parte de tales instituciones. Pero si su leitmotiv no es la pobreza, sino el marxismo-leninismo, van de la mano la 
ayuda armada y la ayuda de impunidad; G. Bush y la CIA ya se conocian desde antes...

La declaración prosigue: "Además las luerzas armadas estadounidenses entrenaron a miles de soldados salvadoreños y en ocasiones tuvieron militares y asesores de inleligencia en el pais centroamericano... Entre otros documentos importanles, que la Comisión de la Verdad eslaría inleresada en esludiar deslaca a un proyeclo conocido como reporte Woemer, que especilica la capacidad mililar salvadoreña y su estrategia para combalir a los grupos guerrilleros. También existe un documenlo elaborado por especialisias de la CIA sobre la exislencia de escuadrones de la muerte y grupos paramilitares de la extrema derecha. Un funcionario del Congreso de los Eslados Unidos indicó que quizás uno de los documenlos más úliles sea el estudio sobre los escuadrones de la muerte, donde se analiza desde las amenazas de muerle"... (Notimex. El Mundo; 7-11-92; p. 8).

Más adelante nos podrán aclarar los miembros de la Comisión AdHoc si también ellos encontraron reticencias inlormalivas luego de su gira por los EE.UU. (11-7-92) donde el Secretario de Estado para Asunlos Latinoamericanos, Bernard Aronson, les olreció "toda la inlormación necesaria" para cumplir su larea de depurar las Fuerzas Armadas. De acuerdo a un edilorial del New York Times, de esos mismos dias, "el periódico crilica a la burocracia de Washinglon por su lenlilud en la entrega de información o pruebas sobre los abusos de auloridad y graves violaciones a los derechos humanos comelidos por oficiales de la Fuerza Armada de El Salvador. De acuerdo al presligioso e influyente rolativo, los miembros de la Comisión "encontraron que las ruedas burocrálicas (en Washington) se mueven demasiado lento"... (Proceso; ${ }^{2}$ 523; pp. 4-5). Más recientes eslán en nuesira memoria las reticencias y las resistencias de la Fuerza Armada y de sus grupos lantasmas (amén de las amenazas) luego de la enlrega del documento linal "Ad-Hoc". (Proceso; No 531; pp. 14-16; 532-536-537...)

Parecería que con este subir y bajar de los Eslados Unidos a El Salvador, de la CIA-Pentágono a la Fuerza Armada, nos estamos saliendo de nuestro escenario económico de los "cafiones-mantequilla". Incluso nos dicen que los aprendices de economia deberiamos hablar sólo de problemas económicos y mirar y mirar hacia el futuro. Lo hecho, hecho está; perdón y olvido, porque a partir del Presupuesto Estalal1993 y gracias al IVA nos quedarán más recursos para educación, salud, obras públicas... mientras vamos reduciendo las partidas de Defensa y Seguridad Nacional. Por ahí nos quiere llevar la publicidad radial y televisiva del gobierno, dando a entender que comenzamos a entrar en 
"el cielo nuevo y la nueva tierra". Sin embargo, lo más económico que existe es todo aquello que hace o deshace al hombre: los derechos humanos. Tan verdad es decir que "lo hecho, hecho eslá" como lo contrario:" lo no hecho o lo deshecho está por hacer y rehacer". No se puede olvidar lo que sigue presente y promete ser fuluro. No se puede perdonar a quien no se considera sujelo de perdón o no quiere pedir perdón, empecinado en defender la eticidad de su conducla. Por desgracia, nos hallamos frente a este problema de las conciencias deformadas que admilen, a modo de moneda corriente, la corrupción, la impunidad y los negocios son los negocios...

Hay que transcender la interpretación economicista o presupuestaria del dilema "caniones-mantequilla" para ver en estas coordenadas lo que bien podemos llamar la intraestructura espiritual y humana, la dignidad del hombre, que se convierten en el primer consumo y la primera inversión de un modelo de economia social. La primera gran demanda de postguerra es el reclamo por la dignidad de las mayorías populares. Más que los destrozos físicos importan los destrozos morales que la guerra ha causado en los autores materiales e intelectuales. En este senlido, "cañones y mantequilla" no representan una simple alternativa presupuestaria, más del uno y menos del otro, sino una contradicción donde la afirmación del primero es la negación del segundo. Al no lomar en cuenta estos valores espirituales, el neoliberalismo no es el modelo económico de posiguerra, por más que hable de liberlad, igualdad y propiedad privada.

A modo de muestreo signilicativo, el tema que más insistentemente destaca el semanario Proceso en los once primeros meses de 1992 son los derechos humanos, sea en referencia directa a los Acuerdos de Paz, a los repelidos iniormes de las Naciones Unidas, a las declaraciones del Secretario General o de sus delegados, sea en los reportes de las Comisiones de Derechos Humanos nacionales y extranjeras... Aparte de otras razones que expliquen la brevedad o simples lineamientos de la reformulación económica en los Acuerdos de Paz, hay una razón fundamental para que este documento dedique la mayor extensión y el mayor delalle a la desarmamentización de unos y a la protección de los derechos humanos de otros. Se ha podido interpretar $-y$ con bastante razón- esta diferencia de espacios escritos como una victoria neoliberal porque las reformulaciones económicas son débiles y accidenlales. Pero lambién podemos leer la hisloria al revés: si se logra implementar toda la primera parte de los Acuerdos de Paz, en lo relerente directa e indireclamente a los derechos humanos, lógicamente se cuestiona el modelo neoliberal. Que esta leclura tenga su porcentaje de verdad lo pode- 
mos deducir de las resistencias militares, gubernamentales y de ciertos grupos oligárquicos al cumplimienlo del centenar de claúsulas pacladas en los Acuerdos de Paz. En el tondo, esto signilica un cambio radical de cullura, la cullura del Quinlo Cenlenario. Es irónico que en eslas conmemoraciones algunos grupos rememoren los hechos de hace doscientos o quinientos años y silencien estoicamente el último medio siglo o el último decenio.

Cerramos esta primera parte con dos de los párrafos finales del editorial que ECA dedicara a "los derechos humanos: la lucha entre la paz y la conirontación". "La reconciliación de El Salvador es imposible sin un irrestricto respeto a los derecho $s$ humanos. Este respeto absoluto impli$\mathrm{ca}$, de hecho, reconocer la supremacia de la vida y de la dignidad humana por encima del Estado y de sus agentes. Estos no pueden actuar arbitrariamente y menos pueden traspasar el límile de la vida, un limite absoluto. El Acuerdo de Paz permile establecer solidamente ese límile; se han hecho esfuerzos, pero éslos aún son frágiles, asi como sigue siendo frágil lodo el proceso de pacilicación. Ambos necesitan de una voluntad política más decidida, que se traduzca en prácticas... El cese del enfrentamiento armado exige la construcción de una nueva casa común para todos los salvadoreños, cuyos cimientos deben ser la verdad, la juslicia, la paz y la cultura de los derechos humanos. Comenzar a fundar dicha cultura no significa sólo hablar de derechos humanos, sino apropiarse de los valores que defienden y proponen, la vida, el primero de ellos, garanlizándolos en la práctica institucional de la sociedad" (ECA, 1992, pp. 330-331).

\section{Consumo versus inversión}

En las primeras y en las acluales ediciones de P. Samuelson aparece otro grático con otra alternaliva que determina el nivel y capacidad de expansión futura de nuestra "curva de posibilidades de producción": la elección entre consumo e inversión. Una primera leclura, muy sencilla, es que por consumo se entiende el grado de salisfacción de las necesidades presentes, mientras que la inversión es la generatriz de la expansión futura. El ahorro será el puente entre el presente $y$ el fuluro. Caminando "río-arriba" sobre los da-

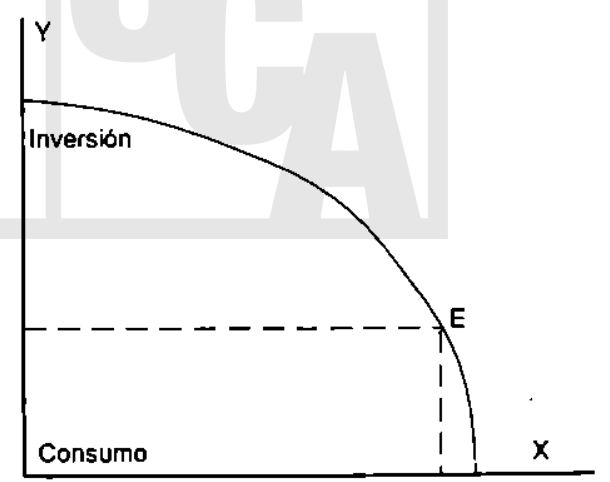


tos estadíslicos que muestran la geslación del PIB, via demanda, ya se nos enciende un pilolo rojo: a precios corrienles las dos macrovariables crecen ostensiblemente; a precios constantes o valores reales el consumo apenas crece, mienlras que la inversión liende a contraerse. Lo sencillo se complica y hay que buscar explicaciones para nuestro presente y para nuestro luluro.

Si la historia es la maestra de la vida conviene hacer una lectura histórica de este diagrama de alternativas. Con los derechos que dan los ańos, volvamos a las primeras ediciones de P. Samuelson y a la $\|^{a}$ postguerra mundial, precedida por la crisis mundial-1930... ¿Cómo leíamos ese grálico? La segunda guerra mundial (precedida por otras guerras civiles) fue lan destrucliva en sus balallas del campo como en los bombardeos de las ciudades que no nos dejó ni consumo ni inversión. Habia que hacer las dos cosas a la vez; y las dos cosas a la vez sólo se podía hacer con trabajo y con sacrificio: Irabajo y sacrificado de todos. Para conjugar trabajo y sacrilicio comunes se creo en muchos paises la cartilla de racionamienlo que asegurase a todos el mínimo necesario. Presionados por la escasez de recursos descubrimos dos cosas: primero, distinguir enlre lo necesario y lo no necesario; segundo, lo productivo que es el trabajo de todos unido al sacrificio de lodos. Trabajo más sacrificio igual a ahorro, igual a inversión. Algunos paises se beneficiaron más que otros de las donaciones (Plan Marshall), pero en cualquier caso la ayuda exlerna caia sobre un lerreno abonado por el trabajo y sacrificio. La Europa del Esle y del Oesle inició así la rula de la recuperación, aunque - por desgracia - esa marcha se viera ensombrecida por las expeclativas de la múlua agresión propias de la "leoría de la coexislencia pacilica". A ello hicimos algún comenlario presenlando cifras.

Cuarenta años más tarde leemos el mismo diagrama en forma bastante diferenle. Comparalivamente tenemos una gran venlaja junlo con un gran inconvenienle. Nuestra ventaja comparativa es la esperanza de poner un punlo final a la solución por la guerra, limilando y anulando, si fuera posible, el presupuesto mililar. El gran obsláculo social es que hemos pasado una guerra, pero la guerra no ha pasado por muchos de nosolros. No acabamos de distinguir entre lo necesario y lo no necesario, entre lo posible y lo imposible, entre lo convenienle y lo no convenienle. Cuando analizamos o explicamos estas alternativas decimos simplemente que esas macrovariables presentan niveles diferentes en los países desarrollados y en los subdesarrollados; ellos están capacitados para producir bastanle de las dos variables, mientras que nuestro "circulo de la pobreza" constriñe el nivel de consumo y reduce la inversión a simple reemplazo del equipo. Llevados del eleclo-imitación, para 
romper el círculo de la pobreza pedimos y nos dan un modelo extranjero, sin anles ponderar que son los hombres, la propia cultura y la disponibilidad de recursos quienes hacen el modelo. Alemanes, japoneses, israelitas..., han conocido en su historia diversos modelos económicos. que a su vez los han ido remodelando porque no lodo era bueno en esos modelos y porque los grandes paises han producido también grandes monstruosidades de las que a veces se arrepienlen. Ahi está el neonazismo dentro de una economía social de mercado, y ahí está la indisciplina israeli frenle a las órdenes de las Naciones Unidas; y ahi eslán las acusaciones de Iraudes financieros en primeros ministros japoneses. La pregunta es si los modelos hacen a los hombres o más bien los hombres hacen y deshacen los modelos. También nosolros hemos conocido una serie de modelos algo difíciles de cualificar por las supervivencias del pasado; digamos que hubo algo de economia de mercado antes de 1980 , algo de economía inlervenida de guerra en la pasada década y ahora un bandazo al neoliberalismo, con el aditivo de economía social en el envoltorio.

El cuestionamiento es si hemos ponderado los grandes limitantes internos para que nos encaje y nos encajemos en este modelo: la escasez de recursos fisico-financieros y el subdesarrollo humano, que de alguna forma hemos comentado en la primera parte. Si la hisloria es maestra de la vida podemos afirmar que no es tan cierto que el crecimiento lleve al desarrollo, sino que más bien el desarrollo lleva al crecimienlo. Lo imposible, to no conveniente y lo no necesario es pretender un crecimiento y un eslilo de vida de paises desarrollados, cuando aparte de la carencia de taclores fisico-financieros, no hayamos desarrollado al hombre. El eleclo-imilación nos lleva a una mala imitación: desarrollar primero las mercancias y cuando juegue el rebalse desarrollar las personas. En esta línea de crecimienlo se restringe la equidistribución y por tanlo el verdadero desarrollo.

Hay dos partes o dos esferas en nuestro Plan de Desarrollo Economico y Social, 1989-1994, algo dificiles de ensamblar. El Plan se inicia presentando "los principios filosólicos", que serían al mismo tiempo principios y metas nacionales. "El hombre es el fin de toda sociedad; la libertad es la base del progreso humano; la igualdad ante la ley es la garanlía de la paz social; la justicia garantiza a cada quien lo que le corresponde; el Eslado desempena un papel subsidiario" (pp. III-IV).

Valga advertir que eslos principios y su explicación están literalmente tomados de una publicación de FUSADES como el preámbulo para pasar "Hacia una economia de mercado en El Salvador" (mayo, 1989). Aforlunadamenle, de entonces para acá, se han pactado los Acuerdos 
de Paz, 1992. Eslo nos plantea un serio dilema: las mismas palabras tienen un signilicado muy diferente leídos desde el Mercado o leidos desde los Acuerdos de Paz. Toda la primera parte de este comentario, que gira alrededor de los "derechos humanos", se centra en la dignidad del hombre, pero no de un hombre individual e individualista a quien sirve el reslo de la sociedad, sino del hombre social que sirve a una sociedad de hombres dignos como él. El ideal de la libertad y de las libertades políticas que, de acuerdo a los cualro discursos anleriormenle citados, habian sido suprimidas o silenciadas, encajan centralmenle en los Acuerdos de Paz. La misma palabra "libertad" enlraña un significado muy dilerente desde la leclura del mercado, quien la aplica por igual al produclor de granos básicos, al monopolio o al oligopolio tisico-financiero. También en las carreleras todos los automóviles son libres pero en los accidentes los más golpeados son los pequeños.

Si algún tema ha sido tratado y maltralado en lodos los medios de comunicación social ha sido el de la justicia y la igualdad ante la ley porque esle clamor se había opacado por las vias civiles y armadas. Desde esla perspecliva el Eslado, en cuanto Gobierno supeditado a los poderes económicos y mililares, podia relegarse a un papel secundario o lerciario mienlras surge el "eslado de derecho". Las mismas palabras encierran significados, no sólo distintos sino hasta contrarios. Desde los Acuerdos de Paz estos ideales humanos se traducen en paclos concre10s, en un largo calendario que marca tiempos y esluerzos de realización. Muy distinta es la vía o los "Postulados Económicos" exigidos desde la perspectiva de la economía de puro mercado: "la propiedad privada, el mercado libre, la competencia, el Estado subsidiario" (pp. 9-10).

Si en la universidad lormamos ingenieros, economistas, administradores..., si investigamos y escribimos sobre la problemálica técnico-social de nuestros mercados, quiere decir que colaboramos con la empresa y tratamos de preparar los mejores prolesionales para el seclor productivo. Pero además de formar filósolos y leólogos, la universidad misma debe sopesar si los medios se adaptan a los fines o si hay contradicciones ente los medios y los lines. ¿Cómo se puede ensamblar, en nuestras acluales circunslancias, una reestrucluración de la sociedad civil, basada en la igualdad, la justicia, la libertad y los derechos humanos, con una estrucluración económica asentada en la propiedad privada, la competencia y el libre mercado, todos ellos discriminanles, y con la post-data de que el Estado no inlervenga en el libre juego entre desiguales? ¿La igualdad y la juslicia puede surgir espontáneamente de la desigualdad estruclural de la propiedad privada o de la capacidad de compelir en el libre mercado? Aclualmente no existen las bases reales 
para que entren a jugar incondicionalmenle los poslulados económicos del simple mercado, so pena de eslerilizar los Acuerdos de Paz y reformular la hisloria conflictiva de los años $1970 \ldots$

Eslo significa que enlre los principios filosólicos (pp. III-IV), leidos desde los Acuerdos de Paz y los postulados económicos del mercado (pp. 9-10) hay que lanzar un puente. Esle puente, que el Plan olicial relega a la segunda parte, es la viga Iransversal y necesaria para Irasladarnos de la paz al desarrollo económico. Cuando al Estado se le adjudican, con carácter subsidiario, los programas sociales de educación, salud-nutrición, vivienda, familia, previsión social, seclor laboral y política ecológica, se están ubicando los pilares básicos para poder transitar de la paz al desarrollo. Sin embargo, eslo no es algo subsidiario o supletorio, en el sentido de menos importante. $O$ lo hace el mercado, 0 to hace el Estado reformulado en sus funciones, o lo hacen terceras luerzas sociales concebidas como corporaciones de utilidad pública..., 0 peligran en el mediano plazo los Acuerdos de Paz. Lo más necesario es lo más conveniente y debe ser lo posible.

Podemos utilizar el principio de inducción, que de los casos particulares avanza a un enunciado general. Hay una frase que repile la genle sencilla, el pueblo, que en tres palabras y los punlos suspensivos dice más que cualquier discurso: "uno de pobre...". El tono de resignada aceplación y los punlos suspensivos resumen loda una historia. Incluso se puede dar vuella a la frase: "el pobre no es uno, es nadie". Es lodo lo visto en la primera parte de esle comenlario. Por sumatoria acumulada de casos particulares (los pobres y los más pobres) llegamos a la conclusión de que el pais, en bloque, liene que lomar conciencia de su siluación: "uno de pobre...". Eslo no es un irrespeto a la bandera o al himno nacional, pues Irecuentemente decimos que somos un pais pobre. Eslo es una conlesión de boca, pero sin propósilo de enmienda; y la razón es que se trala de una mala confesión de boca, porque al decir que somos un pais pobre pensamos en nuestro reducido lerritorio, escasos recursos del subsuelo y cosas parecidas, olvidando la gran riqueza escondida en la población. Hemos hablado de alemanes, japoneses, israelitas...; podemos y debemos hacer una relerencia a la laboriosidad, tenacidad y aguante (además de resignación) del pueblo salvadorefío. Esta es la gran fuerza motriz, aunque latenle, que posibilita el desarrollo del pais, pero que tradicionalmente - aparle de olras marginacionesha estado somelida a los decrelos de salarios mínimos, cerrando toda válvula de aulodesarrollo. Signo de su ingenio y laboriosidad son los montos de remesas de emigrantes que, superando el valor de las exportaciones tradicionales, están manteniendo a flote el actual modelo eco- 
nómico. Signo de su creatividad son las comunidades de repatriados que, en las más adversas condiciones, han creado esas ejemplares cooperativas o comunidades de trabajo, con el delalle de poseer un elevado índice de altabelización. El modelo neoliberal no da signos de prestarles mucha atención, porque no es modelo y porque todo esto lo relega a la asistencia extranjera. Sólo queda que los teóricos y los prácticos geslen los lineamientos de una Nueva Economia Popular.

Ya hemos mostrado en olros arlículos e invesligaciones que la satisfacción de las necesidades básicas es un elemento de reactivación económica Pero hay todavia algo más que producir bienes materiales para la satisfacción de las necesidades básicas; se tratara de anclar el eje del modelo económico en la formación y desenvolvimiento humano de las personas. En consecuencia, lo que los autores del Plan Económico (1989-1994) relegan a la segunda parte, calificada de "subsidiaria" (educación, salud-nutrición, vivienda, seguridad social...). pasa a ser el eje central del de-

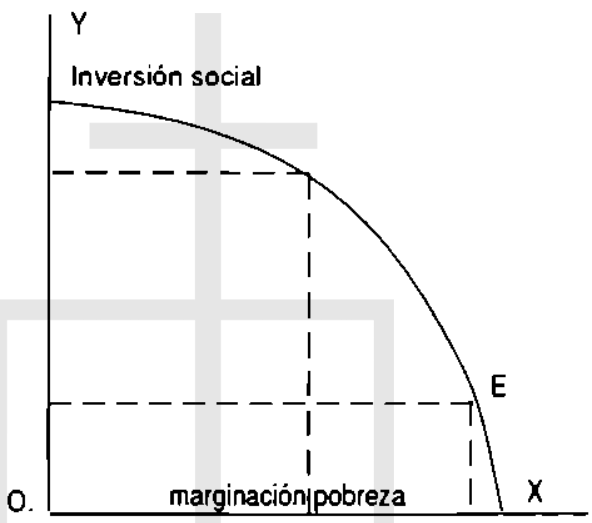
sarrollo. Esto nos permite sustituir en el anterior gráfico las variables inversión-consumo por la nueva alternativa de la inversión social como el medio primordial para corregir la marginación y extrema pobreza, marcando nuevas sendas del desarrollo de $E$ hacia $E^{\prime}$.

Visto con buenos ojos, esle grálico encaja en los lineamienlos del Plan de Reconstrucción Nacional y del FISS, a condición de que eslos proyectos no se utilicen como spots publicilarios para las elecciones de 1994. Encaja también y es parte integranle de los programas de reconversión industrial, que más allá de la tecnologia mecánica requiere toda una prolesionalización de la mano de obra en los Ires seclores económicos y en la "pesada industria" de la Administración pública. Los conceptos de reconstrucción y reconversión llegan a lo profundo de los agentes del desarrollo que son los hombres. Más que de un nuevo modelo económico de macrovariables cuantificables se trata de un nuevo sistema, sustentado en principios sociales, que no nos alrevemos todavia a claificarlo como neo-socialismo para evitar que se nos cuelgue en el árbol genealógico de los "socialismos reales". Es un neo-socialismo inspirado en los Acuerdos de Paz. 
Llamamos así a las puertas de los grandes actores económicos: el Presupueslo del Eslado y el mercado privado. No invocamos aqui a los partidos polílicos que se apropian la represenlación del verdadero pueblo salvadoreno. Nos referimos directamente a la reestructuración de las partidas del presupuesto estatal en un pais que quiere pasar de una sociedad militarista a una sociedad civil y civilizada. Las promesas preelectorales poco valen si no se Iraduce en la distribución de los gaslos públicos. Nos referimos a la reesinucluración de los ingresos estalales, donde pagan directamente menos los que más se benefician de las inversiones físicas y pagan relativamente más los que menos gozan de las inversiones sociales. De todo esto también se ha escrito mucho recientemente. No hay duda de que esta remodelación o neosistemalización económica conlleva una reformulación de las funciones del Estado y de la misma Administración Pública, de suerte que pueda hacer bien lo que debe hacer. Estas reflexiones, soportadas en datos estadísticos, se las hace el Dr. Carlos Briones al preguntarse: "Ajusle eslruclural y desarrollo ¿dónde estamos?" (ECA, 1992, pp. 741-755).

Esta visión supone una reestructuración del mercado en un pais de recursos muy limilados, llamado a mantenerse de momento en niveles de sobriedad en los eslilos de vida, de manera que el desarrollo desde dentro lortalezca el desarrollo hacia ałuera. Desde una visión histórica el Dr. Luis de Sebastián ejemplariza el tema contencioso de "Solidaridad y Mercado" (ECA, 1992, pp. 757-770).

Las escasas citas bibliográficas podian multiplicarse, acumulando la diversidad de arliculos publicados en nuestras revistas ECA y Realidad Económico-Social sobre neoliberalismo, ajuste estructural, políticas macroeconómicas y tributarias, reconstrucción nacional y reconversión induslrial, la nueva economía popular... El presenle comenlario pretende sólo lanzar unos lineamientos económicos desde los principios de los Acuerdos de Paz, que son principios de un modelo social. Las investigaciones y artículos de nuestra u olras instituciones ofrecen aportes lécnicos y concretos para haer factible la paz con desarrollo. No está de más, de vez en cuando, quedarse a nivel de ideas o principios generales sin más aporte esladíslico que el buen senlido común. Con trecuencia, lo no cuantificable o lo sublerráneo puede salvar o puede carcomer cualquier modelo económico.

\section{Entre la élica y la corrupción}

A.P. Samuelson no se le ocurrió hacer un gráfico de curvas de "posibilidades de producción" ubicando en coordenadas la Etica y la Corrupción, aunque en su texto sí habla de corrupción en el mercado y de 
leyes anticorrupción. Repasando nuestra historia, los litulares de nuestros diarios y la juramenlación de la Comisión de la Corrupción, merece la pena dedicarle un diagrama de este par de existenciales contradictorias como puede serlo los virus y los antibióticos. Una vez que ya se hable menos de capitalislas y comunistas, siempre se seguirá hablando del ético y del corruplo, porque eslo es más anliguo y perenne que cualquier sistema económico. Un primer pro-

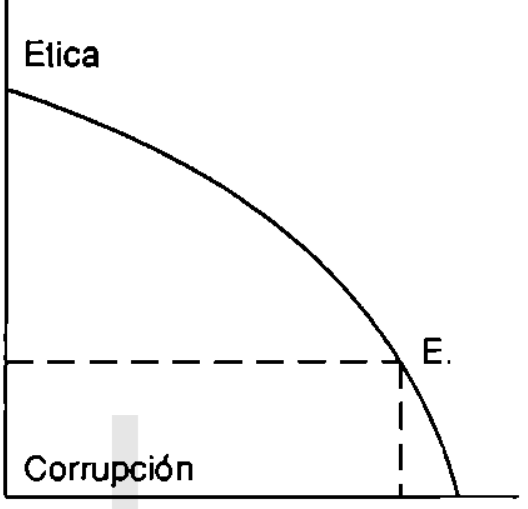
blema es cuanlificar estos valores en un grático, porque el consumo yla inversión los encontramos en la revista del BCR. El gráfico les da úna dimensión hipolética porque parece que abunda más la corrupción que la ética.

Además eslamos cuantilicando sin definir lo ético y la corrupción. Pero esto nos llevaria a hacer un largo recorrido desde la ética de Platón hasla la ética de Millon Friedman "free to choose". Abreviando la historia, basla decir que para que haya un corruplo hacen lalta dos: el que paga y el que recibe, el que hace y el que consiente, el que obedece y el que ordena. El hombre élico es una persona solitaria, fiel a sus principios, hace el bien sin esperar recompensa y confia en que la historia le dé la razón. A partir de esla descripción podriamos deducir que el número de los corruptos duplica al de los hombres éticos; pero eslo no pasa de ser una aproximación. Más acertado será preguntarse de dónde y por qué nace esta cullura de la corrupción.

En un primer sondeo parecería que ciertas profesiones, ciertos cargos y cierlos acontecimienlos propician más la corrupción. En los Acuerdos de Paz nos han aparecido bastante ejemplos. No vamos a extendernos más en la suprema corrupción, compañera de viaje de la luerza armada, que desborda lodos los cauces en los doce años de guerra. En la proclama de los jóvenes militares - Oclubre-1979- podemos escuchar que la riada de la corrupción habia roto todos los diques de los procesos electorales y de las timidas reformas sociales, recordando que junto a los corruplos eslaban los que apoyaban la corrupción. Nunca se habian utilizado expresiones tan fuerles como las tirmadas por ambos interlocutores en los Acuerdos de Paz: reducción, depuración, reeducación... La corrupción generó una cullura de la impunidad. Aunque del pasado se haya dicho suficiente, hay algo que asusta en el presenle y próximo luturo: la delincuencia unilormada o veslida de civil 
que se extiende por la nación a raíz del proceso de desmilitarización. Es alarmanle que los cuerpos de seguridad se hayan Iranstormado en agenles de la inseguridad.

Con los derechos humanos ponen sobre el tapele la corrupción en la administración de justicia. Cuando Mons. Romero condenaba este pecado estructural solía repetir el dicho campesino: "en nuestro país la justicia es como la serpiente, que solo pica a los que andan con los pies descalzos". Ya nos suena a Irase hueca la repelida promesa: se harán las investigaciones pertinenles. Las acusaciones de cornupción han subido hasta la Corte Suprema, pero la plancha de cemento es demasiado gruesa como para que la penetren. Nuestros egresados de derecho descubren un ambiente tortuoso desde sus primeras experiencias judiciales cuando los principios éticos quedan agarrolados, como con alambre de espino, por la letra de la ley. También ha habido liscales amenazados y asesinados al intentar descubrir la verdad. A modo de símbolo, ahi está la eslatua de la justicia, desnudita y con los ojos lapados. Mejor seria que le hubieran cubierto sus intimidades y le desvendaran los ojos para ver la verdad.

Si nos trasladamos al nuevo edificio de la Asamblea Legislativa encontramos que la verdad está partida porque cada fracción política la agarra por una esquina. Aqui la maltraída es la Constitución, que al igual que un poliedro tiene muchos lados y pocos asambleistas abarcan en su tolalidad el espírilu de la ley. La mayoria de volos obedecen a consignas del partido y más que los razonamientos puede la mano alzada, a veces financiada. La corrupción lambién carcome los escaños de los curules (con gran pesar del ius-romanum), aunque siempre distinguimos, como en las peliculas del oesle, el chico bueno del chico malo.

Hay una corrupción de la que poco se habla, la corrupción generada por la propia inflación. Y es que la ińlación ha quedado superada por el estruendo de la guerra. Nuestra inflación ya va a cumplir pronto sus veinte años. Los economistas delinen la inflación como un alza generaljzada y persistente de los precios, de acuerdo a las esladisticas. Las peleas técnicas giran en torno al muestreo signilicativo del IPC y a las referencias del punlo a punto u otras medidas de la inflación. Pero hay un peligro de silenciar su corrupción. En primer lugar, con la inflación, la moneda, que es la medida de valor, pierde su valor y con ella los ciudadanos perdemos nuestros valores civicos. Hay que seguir asignando precios a las cosas; se trata de precios subjetivos, especulalivos o sorpresivos, porque para defenderse de la ińlación se crea más inflación. La inflación se convierte en una guerra civil monelaria con el arma de los precios. Con ello los precios dejan de ser el parámetro equilibrante 
de los valores, como lo pretende la teoria del mercado, y se convierten en causales de la especulación y del ejercicio del poder. Cuando se dice que la inflación es un alza generalizada de los precios se afirma sólo una parcela de la verdad. No lodos suiren por igual la inilación: productores-vendedores, con cierto poder en el mercado, compran relativamente baralo y venden relativamente caro; es decir, se defienden de la inflación creando inflación. Los asalariados y jubilados, detentores de ingresos fijos, son las victimas de la inflación, de acuerdo al adagio, que los precios suben por el ascensor y los salarios por la escalera. A la inilación se la ha descrito como la eulanasia de los jubilados. Sin alargar esta triste novela, veinte años de inflación han generado una conducla inmisericorde en quienes se enriquecen con la inflación y una resignada protesta en quienes ir de compras es 10 mismo que ir de suslos. Es corruplamenle lógico que unos aplaudan la economia de mercado, mientras que otros la crilican porque la sulren.

Esto nos lleva a decir algo sobre la corrupción en los leóricos y políticos dogmálicos, y sus medios de comunicación social. Para que no se piense que sólo enfocamos la cámara de un lado, hemos comentado, con suficienle apoyo bibliográlico, que la corrupción fue una de las causas principales de la descomposición y derrumbe de los "socialismos reales" (ECA, 1991, pp. 675-710). En este mismo comentario nos hemos preguntado si es posible asentar los principios filosólicos de la libertad, igualdad y justicia del hombre lin de la sociedad sobre los discriminantes postulados económicos de la propiedad, libre mercado y libre compelencia. Para deilicar el mercado se le describe en abstracto; a las fuerzas se les llama leyes; a los precios especulalivos parámetros del equilibrio; a la inflación permanenle fenómeno coyuntural; a la competencia imperfecla se le llama seclor moderno-lormal, y a la causi competencia pertecla sector inlormal. Cuando el mercado internacional le pega un suslo al café, se recurre a la Asamblea Legislativa en búsqueda de bonos compensatorios: cuando la Ley de Delensa del Consumidor llega a la misma instilución se le recomienda acogerse a las indicaciones del mercado. El crecimiento hacia fuera descuida el desarrollo desde dentro y las políticas de "salarios reales" protegen más lo primero que to segundo. Las medidas fiscales favorecen y dañan a quienes lavorece y daña la inflación. Los acreedores externos miran los desequilibrios globales de nuestra balanza de pagos, pero nunca se preguntan por qué nació la guerra. Los que cada año arañan el monlo de los salarios mínimos nunca tuvieron en mente presenlar un decrelo de "sueldos máximos". Algo más de lodo esto quedó escrilo bajo el litulo: "El neoliberalismo no es un dogma de fe" (Realidad Económica-Social; 1992, №29.). Los leóricos y políticos dogmálicos poco pudieran hacer sin la colaboración de los medios 
de comunicación social, que describen la verdad en blanco y negro, a sabiendas de que en este pais las denuncias legales por calumnias y tergiversaciones rinden lo mismo que pedir limosna.

Hablando de corrupción, de algo nos tenemos que confesar las universidades del país. No se trata de las cuotas ni de los exámenes represivos o regalados. Se trata de preguntarnos que hacen las 40 universidades por mejorar el esclarecimiento de la verdad social y la cualidad de vida del país. Ya se ha hecho eslogan, a coro, que son tres las funciones de la universidad: la docencia, la investigación y la proyección social. Por ciento, hubo que explicarle al primer proyeclo de Ley de Educación Superior que por investigación universitaria no se entendian las tesinas de los graduandos, ni por proyección social el requisito legal del servicio social de los alumnos. Hemos llegado a una situación donde más universidades equivale a menos universidad, con el riesgo de hacer mutua competencia por incompetencia. Teniendo problemas técnico-sociales más graves en nuesıra región, engahamos al alumnado si bajamos las exigencias de calidad para incrementar el termómetro de la malrícula. Si no gastamos en investigaciones, investigadores y publicaciones que proyecten hacia fuera la crítica constructiva, no cumplimos nuestro deber universitario de servicio, no partidista-político, a la sociedad. Globalmente, nueslra iniraesiructura tísico-académica y sobre todo de calidad humana deja mucho que desear, y con ello los títulos profesionales y el aporte prolesional tienden a devaluarse. Con la excusa de no hacer política no se hace universidad; este mismo argumento se ha blandido desde fuera para castigar física y personalmente a quienes pretenden ser leales a las funciones de la universidad. Ojalá que la ya relocada y cirujeada Ley de Educación Superior, si pasa a la Asamblea, nos encarrile a las universidades hacia el buen servicio en calidad a nuestros graduandos y sobre todo a las mayorias de la sociedad.

Sumando o multiplicando lo hasta aqui dicho, la comupción tiende a compenetrar nuestro comporlamiento social allá donde se ejerce un cier10 grado de poder. Círculo vicioso en que el poder, cualquier clase de poder, propicia la corrupción y la corrupción corroe el poder. De esta forma, el poder crea su propio desprestigio y con la cultura de la cornupción hemos llegado a la incultura del poder. El gobierno entrante se apresura a levantar acusaciones de corrupción en las autoridades salientes, y para limpiar la lachada de su propia corrupción nombra, de entre los suyos, una comisión ad-hoc.

Normalmente los modelos económicos hablan de macrovariables cuantificables para decirnos que vamos bien; pero la macro-invariable de la corrupción puede minar las bases de cualquier sistema socio- 
económico. Las curvas de posibilidades de producción se ven siempre amenazadas por este virus. Algo importante en los Acuerdos de Paz es que han servido a identificar los grandes focos de la corrupción, y decirnos que ahi está el problema. Al aceplarlos y al rechazarlos se están identificando los delraciores y los aclores de la corrupción: los éticos y los antisociales. Pero los Acuerdos de Paz son sólo un primer avance en el logro de la eticidad social. Ahora aparece el papel más que subsidiario del Estado, de la enseńanza como educación (escuelas, colegios, universidades...) y de una manera tan fundamental el papel de la lamilia, de los medios de comunicación social, destacando la responsabilidad de una auténtica formación y praxis religiosa, que nosotros llamamos la inspiración cristiana. Estas han sido unas cuantas respueslas a la difícil pregunta: y usted ¿cómo ve la situación? 